\title{
Uma experiência mão na massa de construção de alarme móvel com Arduino Uno como mobilizadora de competências
}

\author{
Armando Foscarin Neto ${ }^{1}$, Caroline da Silva Furini' ${ }^{2}$, Èvora Nirvana \\ Gomes $^{3}$, Adriano Teixeira' ${ }^{1}$. \\ ${ }^{1}$ Instituto de Ciências Exatas e Geociências ICEG - Universidade de Passo \\ Fundo. ${ }^{3}$ Faculdade de Educação FAED - Universidade de Passo \\ Fundo.BR 285. São José I Passo Fundo/RS I CEP: 99052-900. \\ ${ }^{2}$ B-LAB Learning Space- Pátio da Xv, Loja 14 Rua XV de Novembro 200, \\ Centro I Passo FUndo/ RS I CEP 99010-090.
}

\begin{abstract}
This article presents the experience of an Arduino Uno Alarm building workshop in a Creative Learning Laboratory, called the X. The same was structured on the skills and premises of the Maker movement, having the possibility of creation through the experience "hand in the mass". It was sought to detail the workshop and reflect on the contributions of this experience to the students and the process of structuring new concepts and consequent learning, also recognizing what can be improved in the next workshops.

Resumo. Este artigo apresenta a vivência de uma oficina de construção de um Alarme com Arduino Uno, em um Laboratório de Aprendizagem Criativa, denominado de X. A mesma estruturou-se sobre as habilidades e premissas do movimento Maker, tendo a possibilidade de criação através da experiência "mão na massa”. Buscou-se detalhar a oficina e refletir sobre as contribuições dessa experiência aos estudantes e ao processo de estruturação de novos conceitos e consequentes aprendizados, reconhecendo, igualmente, o que pode ser aperfeiçoado nas próximas oficinas.
\end{abstract}

\section{\{135303,161786, teixeira\}@upf.br, carolsfurini@gmail.com}

\section{Introdução}

As pesquisas direcionadas à compreensão da educação do século XXI e das competências exigidas em uma sociedade do conhecimento e tecnológica, remetem à necessidade de modificações nas concepções acerca da aprendizagem e do modo como ela ocorre. Não é recente a ideia de proporcionar aos estudantes, independente da faixa etária, a autonomia no processo educacional, necessária para despertar o protagonismo e desenvolver habilidades que não são alcançadas por meio da execução tradicional das atividades.

A educação mão na massa, principal característica do movimento Maker, foi introduzida na educação, como uma forma de acreditar no processo como grande potencializador da autonomia e do desenvolvimento dos estudantes por meio da experiência e do compartilhamento.

Nesse sentido, o movimento vêm ressignificando o papel dos estudantes e possibilitando uma aprendizagem que valoriza os conhecimentos prévios, instiga a curiosidade, a criatividade e propõe uma nova forma de resolução de problemas, o erro é valorizado como uma oportunidade e a experiência proporciona aos participantes a construção de conhecimentos com maior significado. 
VIII Congresso Brasileiro de Informática na Educação (CBIE 2019)

Anais do XXV Workshop de Informática na Escola (WIE 2019)

Pensando em proporcionar um momento de criação e execução de um projeto, a partir das concepções do movimento "mão na massa", o desenvolvimento da oficina de construção de um alarme utilizando Arduino se deu objetivando oportunizar aos participantes a compreensão dos conceitos de robótica e programação, da ciência e da compreensão do processo, além de utilizar recursos de código aberto, permitindo a reinvenção por parte daqueles que queiram desenvolver outros projetos utilizando as mesmas ferramentas.

Os estudantes participantes da oficina se depararam com uma diferente abordagem sobre tecnologia, desmistificando algumas compreensões e aprendendo de forma divertida, enquanto instigados sobre as suas motivações em relação à construção do alarme e desafiados a resolver problemas encontrados durante a execução da atividade, apresentando soluções de forma criativa e identificando e corrigindo possíveis erros enquanto colocam a mão na massa.

Desse modo, o presente artigo foi estruturado apresentando primeiramente alguns conceitos a respeito do movimento maker, ou, aprendizagem mão na massa, descrevendo o espaço onde ocorreu a oficina, que, desenvolvida em laboratório de aprendizagem criativa, objetiva $o$ desenvolvimento de habilidades e competências nas crianças adolescentes imprescindíveis no mundo atual.

Após, descrevemos o modo como ocorreu a oficina, apresentamos a descrição técnica, os recursos utilizados e o modo de funcionamento do artefato construído. Serão relatadas também as etapas e como se chegou à finalização do projeto. Ainda, detalhamos quais os recursos e ferramentas utilizadas, qual foi o papel do mentor no processo e quais aspectos foram percebidos junto às crianças ao longo da realização da oficina, no que se refere à motivação, as diferentes finalidades propostas por eles encontradas para o alarme, quais as dificuldades encontradas na atividade e potenciais melhorias para próximas edições, com o objetivo de demonstrar como a execução da atividade, a utilização dos recursos de forma colaborativa e a abordagem mão na massa potencializa a construções conhecimento com maior sentido e representatividade.

\section{Aprendizagem "mão na massa" - movimento "Maker"}

$\mathrm{Na}$ obra Educação no século XXI, tendências, ferramentas e projetos para inspirar (Young Digital Planet, 2016), podemos encontrar uma tendência descrita como personalização presente na educação moderna, que, diferente da individualização, quando o estudante não é o centro do processo, ocupando o professor esse papel, compreende uma dinâmica em que o estudante é protagonista do processo de aprendizagem, reconhecendo seus interesses, metodologias de aprendizagem de preferência e identificando o seu próprio objetivo no processo, apropriando-se de tecnologia e, assumindo o professor, o papel de mentor.

Essa é uma perspectiva e abordagem que deve ser observada quando pensamos em educação no século XXI, que não exclui o professor mas que, na condição de mentor, assume uma nova responsabilidade: conduzir e auxiliar o estudante no processo de aprendizagem que vai ser desenvolvido por ele mesmo, a quem se confere autonomia e que pode oportunamente assumir o protagonismo do seu aprendizado e, a partir dos seus interesses, desenvolver habilidades e competências como a criatividade, análise crítica, capacidade de resolução de problemas complexos, dentre outras.

Nessa perspectiva, colocar a mão na massa para os estudantes representa a possibilidade de aprender executando projetos, criando, construindo, configurando uma ruptura na estrutura convencional, caracterizada pela informação e reprodução sistemática de conteúdos. Quando os 
VIII Congresso Brasileiro de Informática na Educação (CBIE 2019)

Anais do XXV Workshop de Informática na Escola (WIE 2019)

estudantes iniciam algum projeto, mesmo desde a prototipação de algo, o processo é colaborativo, e a aprendizagem ocorre nesse processo de modo que os participantes, por meio da testagem de hipóteses, identificação e solução de problemas e compartilhamento de novas ideias, vão se apropriando do conhecimento na medida em que testam e experimentam.

Para Lave (1988 apud Samagaia e Neto, 2015), o processo conduz o aprendiz a aprender aquilo que está apto ao mesmo tempo em que o torna apto. Quando um objeto finalizado é manuseado e após os aprendizes têm a oportunidade de observá-lo a partir de outras perspectivas advindas de um processo de criação do objeto, enquanto se concentram na realização das etapas, os estudantes compreendem, identificam e internalizam conhecimentos mais complexos sobre os elementos envolvidos no processo de criação de forma natural e indireta.

O mentor nesse sentido é responsável pela condução e observação do processo, que nessa abordagem, torna-se mais importante que o produto final. Em uma sistematização de experiências compartilhadas em um workshop realizado pela Porvir ${ }^{1}$ em 2016, que reuniu diversos profissionais, encontramos o relato do professor da Universidade de Stanford, Paulo Blikstein, que aponta: "Uma das coisas mais importantes da educação mão na massa é fazer com que o professor preste mais atenção no processo do que no produto, o que é mudança de paradigma muito grande em relação à educação tradicional, que olha para a prova, que é o produto." (2016). Nesse sentido, o movimento maker representa mais do que uma mudança nos métodos, mas uma mudança de concepção, que beneficia todos os envolvidos no processo.

Como descreve (Samagaia e Neto, 2015) o movimento maker veio de uma tradição conhecida com "do it yourself", ou seu desdobramento, "do it with others" que consiste na organização de pessoas de diferentes áreas direcionadas à ciência e tecnologia que conjuntamente dão suporte à construção dos projetos dos pares, valorizando a experiência e utilizando de projetos criados no próprio grupo ou aqueles disponibilizados por meio de compartilhamento online. Ainda, após execução e melhorias, o projeto é compartilhado, permitindo o acesso facilitado, gratuito e coletivo, configurando o movimento maker como um movimento que prima pelo máximo compartilhamento de ideias, projetos e concepções, utilizando poucos recursos.

O ambiente também é considerado no processo, assumindo importância no estímulo da criatividade e desenvolvimento das habilidades dos estudantes, nesse sentido, a configuração do espaço e o modo como interagimos nele também dialoga com o movimento maker. Um ambiente não convencional, e voltado para a aprendizagem mão na massa possibilita que os estudantes sintam-se livres para desenvolver e executar suas ideias com maior confiança e segurança no processo.

\section{Sobre o B-LAB - Learning Space}

O B-LAB Learning Space $^{2}$ é um laboratório de aprendizagem criativa voltado para o desenvolvimento de competências como criatividade, senso crítico e resolução de problemas, características essenciais do mundo moderno, apontadas como principais competências a serem desenvolvidas segundo o Fórum Econômico Mundial.

O design inovador do ambiente colabora com a execução das atividades despertando o potencial criativo dos participantes, que desenvolvem ideias e criam novas formas de utilização do

\footnotetext{
${ }^{1}$ http://porvir.org/especiais/maonamassa/

${ }^{2}$ https://www.b-lab.us/quem-somos/
} 
VIII Congresso Brasileiro de Informática na Educação (CBIE 2019)

Anais do XXV Workshop de Informática na Escola (WIE 2019)

espaço, tendo liberdade para o desenvolvimento de projetos e contanto com o uso das tecnologias disponibilizadas e auxílio dos mentores no processo.

Tanto nas atividades regulares quanto nos cursos rápidos, como exemplo, na oficina de construção do alarme, o B-LAB Learning Space busca desafiar as crianças e adolescentes participantes, propondo situações, cenários e atividades complexas, instigando a sua resolução, em um processo colaborativo, em que ao estudante é oportunizado refletir, testar e propor, de forma divertida, possíveis soluções para o contexto ou problema proposto. Dentre as atividades ofertadas pelo B-LAB Learning Space, destacamos as oficinas que consistem em atividades de, no máximo 12 horas de duração em que as crianças são chamadas a vivenciar um processo maker que vai das definições do projeto até a construção de um protótipo funcional do aparato escolhido.

Em um contexto global, estamos diante de uma sociedade conectada, com novas tecnologias desenvolvidas a cada dia, e um profissional do futuro que ocupará cargos ainda não existentes, irá se deparar com situações e problemas ainda não existentes. Nesse sentido, ter habilidades e competências como criatividade, capacidade de resolver problemas complexos, dentre outras, são exigências que o cenário nos apresenta.

\section{4. "Afaste-se, gênio pensando!"}

A oficina aqui detalhada, foi intitulada de "Afaste-se, gênio pensando!", sendo direcionada para 11 estudantes de 9 a 12 anos e ministrada no B-LAB Learning Space. O objetivo principal era possibilitar que o público alvo vivesse a ciência de forma divertida e prazerosa. E a resolução de problemas, se bem estruturada, poderia assumir tais conotações, além de despertar curiosidade para as ciências em geral. A oficina foi dividida em dois encontros, totalizando aproximadamente 8 horas. Durante os encontros, alguns dos estudantes tiveram uma primeira experiência com a robótica, desconstruindo a ideia de que a mesma era somente a construção de Robôs humanoides, com os quais a indústria cinematográfica os condicionou a pensar, bem como, tiveram um contato inicial com a programação.

Foram utilizados como materiais didáticos, plataformas de desenvolvimento open source ${ }^{3}$ para hardware e software, tendo o software gratuidade total. Usou-se como plataforma de desenvolvimento o hardware Arduino e, para o desenvolvimento do software, houveram duas etapas: Scratch For Arduino (S4A) e subsidiariamente a própria IDE Arduino.

A escolha desta combinação de ferramentas de desenvolvimento deu-se por conta de sua natureza open source, que possibilita, uma vez acabada a oficina e utilizado o alarme, desmontar o projeto e, com as mesmas ferramentas, dar vida a novos projetos.

Durante o desenvolvimento da atividade, os estudantes foram divididos em duplas para melhor desempenho da metodologia de aprendizagem, que preza pela colaboração e discussão das problemáticas entre os pares, incentivando o trabalho conjunto e a ampliação da rede de aprendizagens. Para cada dupla foram atribuídos um notebook e um kit para a realização da oficina, sendo este composto por: 1 Arduino; 1 Cabo de conexão USB; 1 Sensor de movimento PIR ${ }^{4}$; Buzzer'; 1 Led vermelho e; 7 Cabos de conexão macho-fêmea.

\footnotetext{
${ }^{3}$ Código-fonte de um software que é aberto e livre para qualquer um que desejar o acesso; em nosso caso, utilizamos Linux.

${ }^{4}$ Sensor infravermelho passivo, que detecta movimento e presença.

${ }^{5}$ É um componente eletrônico para sinalização sonora, adicionando efeitos aos projetos.
} 
Após o contato inicial com o kit, os estudantes conheceram o Arduino, suas funcionalidades e algumas aplicações. Além disso, foi necessária uma explicação sobre polaridades, positivo e negativo, tanto no LED, quanto no Buzzer e no Sensor PIR, explicando a importância destas definições para um correto desenvolvimento das atividades.

A fim de compreender quais eram os desejos dos participantes ao realizarem a oficina, cada um dos estudantes teve espaço para expor o que faria com seu alarme. As respostas foram variadas, desde a proteção do próprio quarto contra "invasões" de irmãos, ao propósito de vigiar as dependências da avó, que sofre de doença grave. A partir dessa exposição inicial, reconhecendo as diferentes possibilidades de aplicação do projeto, iniciaram-se as instruções e construção do alarme. A primeira etapa foi conectar o Arduino ao notebook, sendo que, cada estudante deveria fazer o procedimento individualmente, reforçando as definições vistas anteriormente.

Para que o Arduino pudesse ser utilizado na plataforma S4A foi necessário acessar ao IDE da placa eletrônica, sendo gravado no mesmo, um firmware 6 . Esse procedimento foi guiado pelo mentor, que explicou passo a passo, sem o auxílio de telas, evitando que os estudantes copiassem o que estava sendo feito. $\mathrm{O}$ procedimento guiado verbalmente potencializa o papel de protagonista do estudante. O processo é rápido, pois o firmware é pré instalado nas máquinas utilizadas.

Havendo problemas ou encontrando dificuldades nas etapas, a intervenção do mentor se deu na repetição da explicação da parte técnica, de forma individual. Mas isso só ocorreu após a exposição do que foi feito pelo estudante, que deve revisar e expor a execução da atividade, tentando encontrar o erro e a partir da sua identificação encontrar possíveis soluções.

Após essa primeira etapa, o objetivo foi entrar no ambiente S4A. Com o Arduino ainda conectado ao notebook, ao acessar o programa, o mesmo é reconhecido e possibilita a continuidade das atividades. Considerando que parte do grupo não está familiarizado com Arduino e S4A, são apresentadas as principais funções do software, bem como suas características. No momento seguinte, receberam a tarefa de ligar um LED, isso porque, a mesma envolve as duas plataformas mencionadas anteriormente.

Dentro da placa Arduino Uno (Figura 1), o pino $13^{7}$ foi o escolhido para a atividade, em virtude de possuir um resistor interno que não necessitaria da introdução de outro componente eletrônico, simplificando a atividade. Uma vez acomodados os LEDs em seus devidos pinos, sendo Positivo o pino 13 e Negativo o pino GND, adjacente ao pino 13, inicia-se a parte de programação.

\footnotetext{
${ }^{6}$ Código escrito no hardware, a fim deste se comunicar com outro programa.

${ }^{7}$ A placa Arduino Uno possui 14 pinos que podem ser configurados como entrada ou saída digitais, conforme a necessidade de seu projeto. Estes pinos são numerados de 0 a 13.
} 
VIII Congresso Brasileiro de Informática na Educação (CBIE 2019)

Anais do XXV Workshop de Informática na Escola (WIE 2019)

Figura 1 - Placa Arduino Uno, com a identificação dos Pinos de 0 a 13.

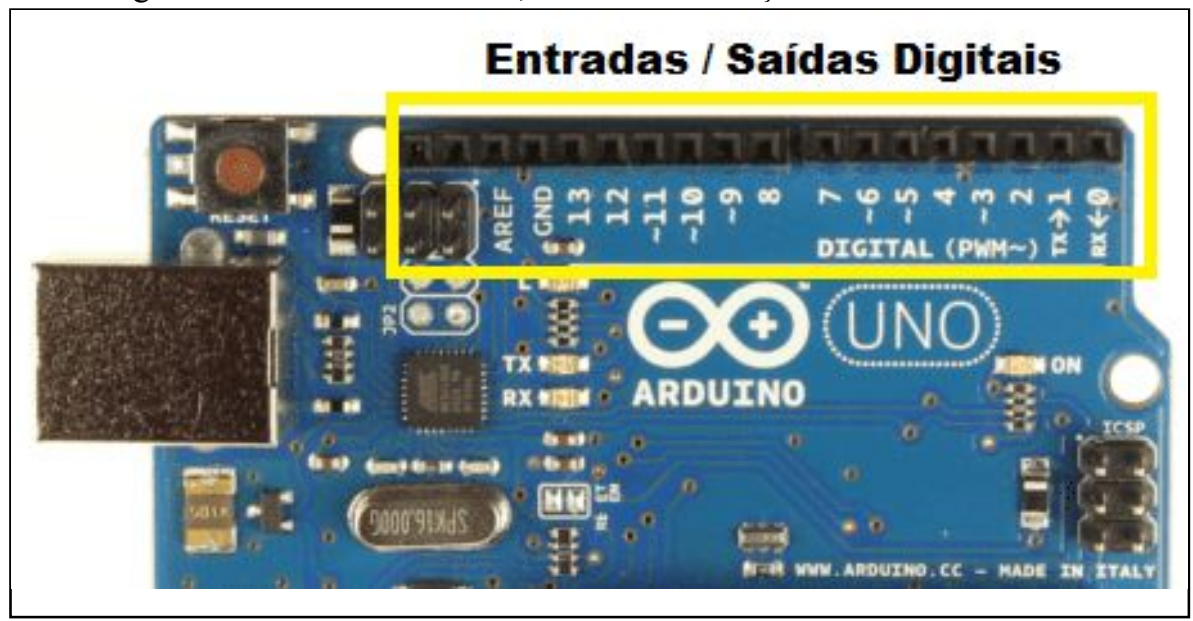

Fonte: https://www.embarcados.com.br/pinos-digitais-do-Arduino/.

Para que os estudantes compreendessem o processo de criação e execução de um código, inicialmente utilizamos dois comandos básicos, que possibilitaram a visualização de resultados imediatos, como podemos analisar no código a seguir (Figura 2):

Figura 2: Código para ligar o LED.

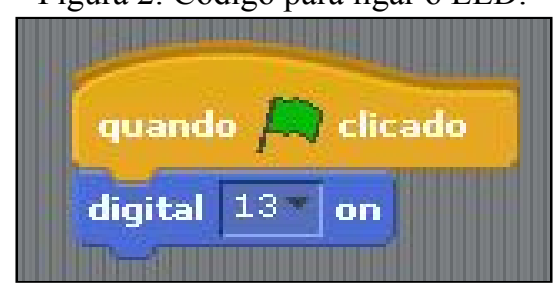

Fonte: Autores.

Na sequência, questionou-se como seria possível fazer o caminho inverso, ou seja, apagar o LED que se manteve sempre aceso com a programação anterior. O papel do mentor, nesse cenário, é o de fomentar a reflexão e a criação de hipóteses e não o de responder as dúvidas que surgem; dessa forma, a pergunta foi lançada à espera de soluções e diferentes ideias advindas dos estudantes. Caso não conseguissem chegar a uma conclusão, seriam convidados a repensar o percurso, até acharem a solução ideal. Por ser algo totalmente novo para alguns e com certa aproximação para outros, buscou-se dividir o grande problema em partes, facilitando o entendimento de cada momento necessário na programação.

Uma vez apagado o LED, os participantes foram desafiados a fazer com que o LED piscasse em sequências de um segundo. Desta vez não couberam mais intervenções abertas por parte do mentor, somente intervenções individuais, questionando sobre a "lógica de funcionamento de uma luz que pisca", na busca pela ampliação da programação .

Ao executar o código da Figura 3, os estudantes perceberam que o mesmo não gerou o resultado desejado uma vez que não houve uma sequência, tendo o LED acendido uma única vez. Nesse momento, o mentor introduziu o que eram os laços de repetição, sugerindo a inserção deste e 
VIII Congresso Brasileiro de Informática na Educação (CBIE 2019)

Anais do XXV Workshop de Informática na Escola (WIE 2019)

posterior teste. Os educandos assim o fizeram (Figura 4) e obtiveram o LED piscando, conforme suas expectativas iniciais.

Figura 3: Código para piscar o LED uma vez.

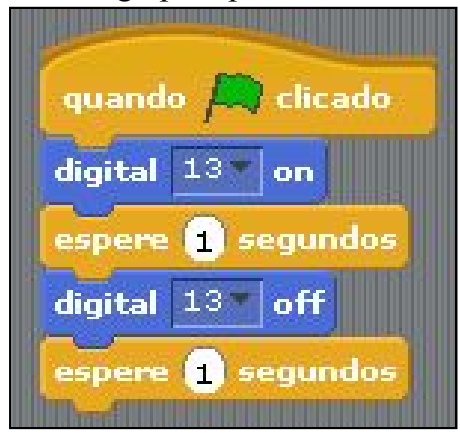

Fonte: Autores.
Figura 4: Código para piscar o LED continuamente.

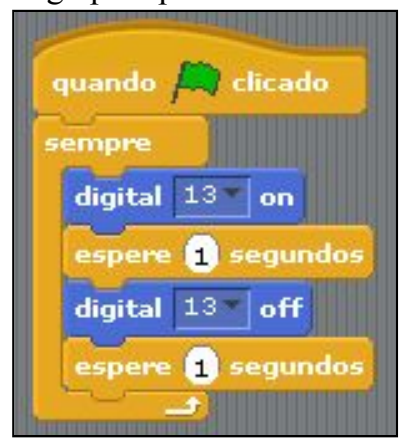

Fonte: Autores.

Após terem concluído esse desafio, continuaram as atividades com o sensor de presença. Inicialmente as instruções eram para uma correta conexão dos cabos entre sensor e placa, usando os pinos 5V, GND e o pino 3 (Figura 5), para recepção de dados. O LED utilizado foi inserido no pino 13 e o Buzzer no pino 7, segundo instruções do esquema a seguir:

Figura 5: Conexão entre sensor e placa

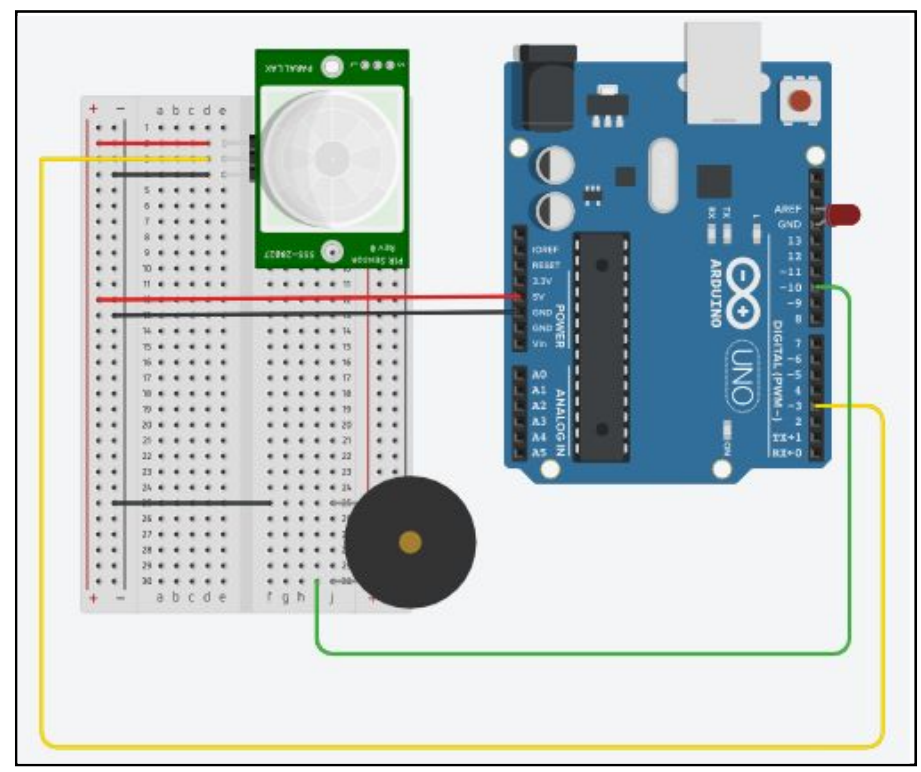

Fonte: Autores.

Com relação ao código criado anteriormente, neste momento, necessitou uma adaptação por apresentar um novo desafio na programação. Os estudantes precisaram inserir a condição "se" (Figura 6), a fim de que, na presença de algo, o LED acendesse e o Buzzer apitasse; na inexistência de movimento, o mesmo se manteria apagado. Tais adaptações foram fundamentais para o correto funcionamento do projeto desenvolvido. 
VIII Congresso Brasileiro de Informática na Educação (CBIE 2019)

Anais do XXV Workshop de Informática na Escola (WIE 2019)

Figura 6: Código com a condição "se".

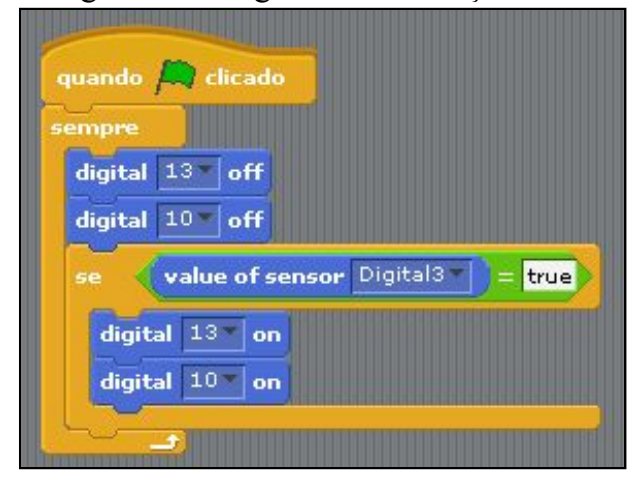

Fonte: Autores.

Uma vez concluídas estas etapas, passou-se à configuração do sensor para que pudesse ser utilizado em suas preferências, no caso, a que distância o Alarme começará a funcionar, acendendo LED e Buzzer simultâneamente. Este sensor utiliza dois trimpot ${ }^{8}$, para o ajuste de tempo e sensibilidade (Figura 7).

Figura 7: Dois trimpot.

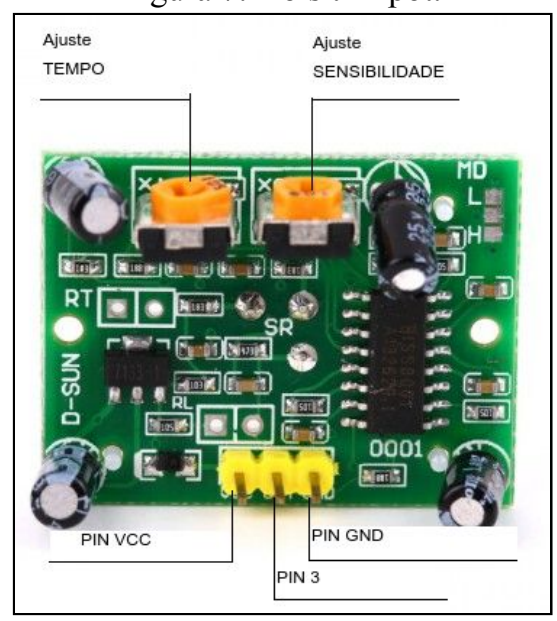

Fonte: Autores

Para concluir as atividades desta oficina e levando em consideração as dificuldades para gravar com efetividade o código escrito no próprio Arduino, decidiu-se passar para a IDE própria deste hardware. Vista a complexidade de compreender e compilar um código em linhas para estudantes que estavam tendo um primeiro contato com a robótica e a programação, o mesmo foi passado já previamente escrito e controlado, para que somente fosse gravado no Arduino.

Ao final, o desafio para os estudantes foi a criação de uma caixa que suportasse o Arduino e suas conexões (Figura 8), projetando perfurações para que o próprio sensor pudesse ficar à vista, juntamente com o LED e o Buzzer.

\footnotetext{
${ }^{8}$ Caracteriza a regulação do dispositivo.
} 
VIII Congresso Brasileiro de Informática na Educação (CBIE 2019)

Anais do XXV Workshop de Informática na Escola (WIE 2019)

Figura 8 - Suporte para o Alarme.

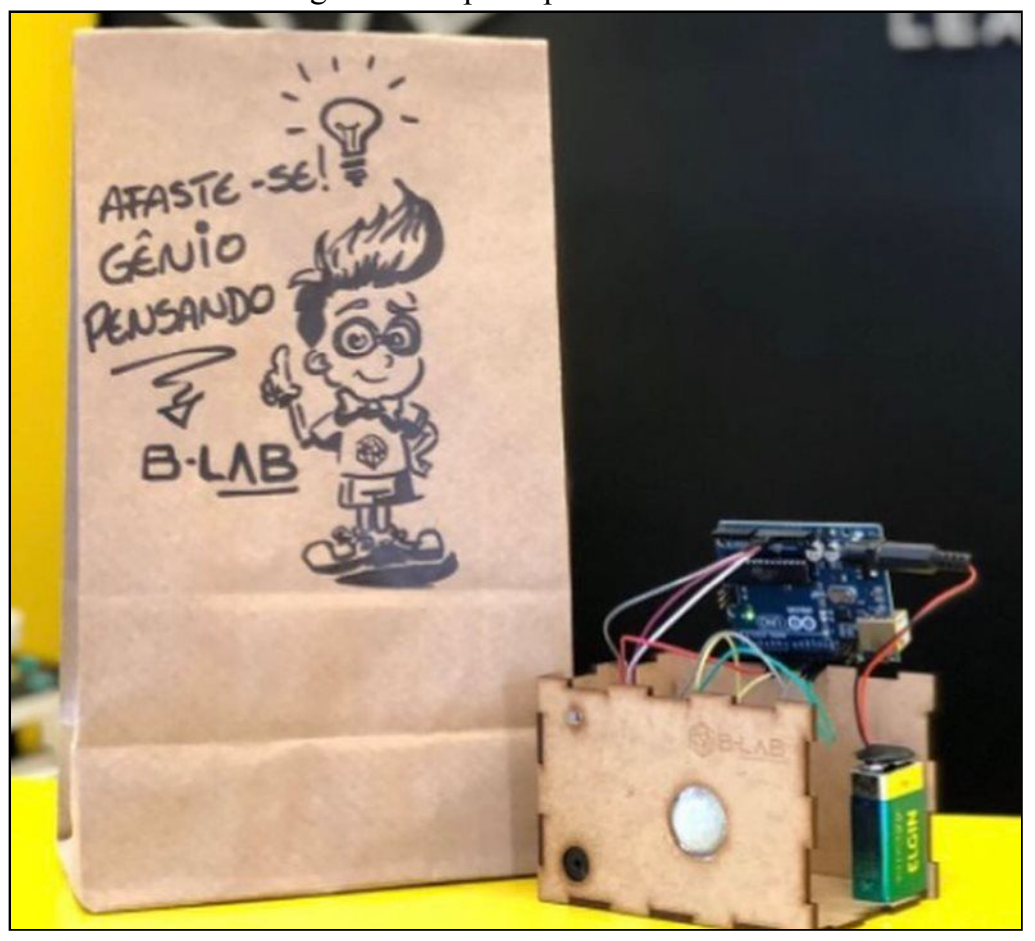

Fonte: Autores.

\section{Reflexões sobre a oficina de Construção de um Alarme}

A partir do percurso vivenciado na oficina, o primeiro ponto que se faz visível é a maneira como esta foi estruturada e colocada em ação, caracterizando um momento propício de criação de novos conceitos na área de ciência da computação, mobilização de conceitos escolares como é o caso da Distância e de protagonismo dos estudantes. O aprendizado de algo totalmente novo, quando passa pela experiência de colocar a mão na massa, ganha um significado maior para aquele que aprende. Dessa forma, há um movimento de apropriação de novos saberes, em que, o educando incorpora aos conhecimentos já constituídos, novas estruturas e conceitos, a partir da prática.

A construção do alarme ocorreu de maneira gradativa, valorizando o percurso de criação de cada um, por isso, em vários momentos o atendimento aos estudantes se fez de maneira individualizada, pois cada um havia avançado à sua maneira. Nos estudos de Dougherty (2012 p.5, apud GOMES et al., 2017, p. 304) visualizamos que "nós deveríamos parar de perguntar como podemos testar o conhecimento do estudante e passar a perguntar o que o estudante pode fazer com o que ele sabe. Quando ele constrói um artefato, este objeto é a demonstração do que ele aprendeu, o objeto provê a evidência da aprendizagem".

Compreendemos que ainda que a oficina tenha o alarme como objeto final de criação e construção, cada estudante o fez a partir de seus anseios, motivações, conhecimentos prévios, dentre outros. Assim, o percurso de aprendizado e o processo no qual os estudantes estiveram comprometidos durante essas horas de oficina, teve maior representatividade e significado para cada um deles.

Em relação à motivação, se fez importante para os estudantes o papel do mentor em levá-los a reconhecer qual era o desejo ao buscar a oficina. Assim, puderam direcionar o alarme para 
VIII Congresso Brasileiro de Informática na Educação (CBIE 2019)

Anais do XXV Workshop de Informática na Escola (WIE 2019)

diferentes objetivos, fossem eles de cunho lúdico ou para alguma necessidade de maior responsabilidade. A partir dessa inquietação inicial e do pensamento sobre para que precisavam do alarme, a construção deste ganhou maior sentido. É fundamental que processos educativos da contemporaneidade ajudem os jovens a ver sentido na tecnologia.

Percebemos como um desafio, o pouco conhecimento de programação dos participantes, por isso a adaptação da oficina, compilando um código pronto para os estudantes, tendo estes que realizar a gravação do código no Arduino. De qualquer forma, a condução da oficina possibilitou que os mesmos desenvolvessem conhecimentos de Condicionais, Laços de Repetição, Estrutura Lógica e manutenção de sensores de forma natural e gradativa. Como forma de aperfeiçoamento, caso o público já tenha maior contato com a linguagem de programação, reconhecemos a possibilidade de ampliação da carga horária e, assim, o desenvolvimento do código, complexificando o desafio e a aprendizagem no processo.

Ao final da oficina, todos os alarmes foram testados, proporcionando mais um momento de diversão e empolgação para os participantes. Os alarmes foram dispostos no formato de labirintos e a tripulação do B-LAB Learning Space, além das crianças, foram desafiados a passar pelos alarmes, sem que eles soassem. Em todas as tentativas, ninguém conseguiu escapar do apito, ocasião em que algumas crianças manifestaram "Nossa! Esse alarme é muito sensível!", "Quero ver meu irmão pegar minhas coisas agora!", ou ainda "Sensibilidade 2.000!", demonstrando estarem muito felizes com os resultados conquistados.

Posterior, há um feedback dos pais externando a felicidade dos filhos por terem construído algo, salientando a satisfação em relação à criação, independentemente do objetivo a que se propôs o alarme, que foi de motivação individual, demonstrando que os alarmes têm servido para as funções propostas inicialmente.

\section{Referências}

GOMES, Eduardo Borges et al. A Experiência de Implantação de uma Disciplina Maker em uma Escola de Educação Básica. In: Anais do XXIII Workshop de Informática na Escola (WIE 2017). Recife: SBC, 2017. Disponível em: http://www.br-ie.org/pub/index.php/wie/article/view/7248

PORVIR. O aprendizado que passa pelas mãos. Disponível em: http://porvir.org/especiais/maonamassa/. Acesso em: 10 jul. 2019.

SAMAGAIA, Rafaela; Neto, Demétrio Delizoicov. Educação científica informal no movimento "Maker". In: X Encontro Nacional de Pesquisa em Educação em Ciências - X ENPEC. Disponível em: http://www.abrapecnet.org.br/enpec/X-enpec/anais2015/resumos/R0211-1.PDF 